\title{
Sciences come alive for first-year university students through flipped classroom
}

\author{
Thalluri, Jyothi ${ }^{\mathrm{a}}$ and Penman, Joy ${ }^{\mathrm{b}}$
}

${ }^{a}$ School of Pharmacy and Medical Sciences, University of South Australia, Australia, ${ }^{\mathrm{b}}$ Nursing and Midwifery, Monash University, Australia.

\begin{abstract}
This paper discusses an initiative implemented for on-campus first-year nursing and midwifery students studying Human Body, a course which covers core Anatomy and Physiology, at a South Australian university. The initiative implemented was flipping the classroom with the objective of facilitating active learning. Formal lectures were replaced by student-centred activities that encouraged studying the topics before coming to class, discussing their understanding and misconceptions, and determining the new learning that was achieved during class.

A post-flip classroom survey was used to gauge the impact of the initiative on students. Of the 532 students enrolled, 188 students completed the questionnaire for a 35\% response rate. The survey queried students' views about the flipped classroom, their experiences with the teaching format, the learning that transpired, engagement with content and study materials, what they liked about it, impact on their test scores, and areas to improve the initiative. Findings showed $60 \%$ preferred the flipped classroom approach. Students were actively engaged with and challenged by the content. They actively participated and learned, and found the flipped classroom to be interactive,enjoyable and fun. In fact, $77 \%$ of respondents recommended flipped classroom to future students.
\end{abstract}

Keywords: University teaching formats; Flipped classroom; Active and collaborative learning; Technology advancement. 


\section{Introduction}

One of the recent developments in higher education is the flipped classroom, which pertains to learning that occurs outside the classroom and subsequently discussed inside the classroom (Baker 2012; Barrett 2012). In flipping the classroom, educational institutions are able to provide a high quality, flexible, and interactive platform for students (Educause Learning Initiative 2012) where cognitive skills and abilities such as reflecting, analysing, and evaluating are strengthened (See \& Conry 2014).

The motivations for adopting the flipped classroom in higher education are many, including: diversity in students' demographic characteristics; need to be flexible to address diversity; reduced contact time with students; propagation of superior materials; technological advancements; and access to a wide range of resources. There is also the need to teach students to be active, independent and self-directed in their learning, whilst at the same time, providing meaningful engagement and support for their learning. Flipping the class was viewed as one way to address these needs.

Flipped classroom as a teaching and learning initiative was trialled by science academics for a group of first-year on-campus students undertaking a Human Body course in a metropolitan university campus in South Australia. The initiative was conducted by replacing traditional lectures with flipped lectures that were aided by providing out-ofclassroom content and activities, thus allowing more classroom time for active learning and peer collaboration (See \& Conry 2014). The purpose of this paper is to discuss on-campus students' perceptions about flipping the classroom for some aspects of the Human Body course.

\section{Flipping The Classroom}

The course that was flipped was Human Body 1 with a unit value of 4.5, where one unit is calculated to be about 35 hours of work. Initially, the teaching arrangement for this course involved weekly three-hour lectures and two-hour tutorials/practicals per study period. Human Body 1 was common to the Nursing and Midwifery curricula and offered on- and off-campus. Nine topics on the body systems were covered. Four topics were flipped, while the rest were taught via traditional lectures.

In flipped classroom, lectures (averaging 1.5 hours/week) were pre-recorded and made accessible to students at the beginning of the course, before the face to face flipped lectures. The concept-based recordings were deliberately shortened and streamlined. Also, students were provided with readings and additional resources, such as relevant YouTube videos and online materials, for further engagement and understanding. These clips were short (15 to 35 minutes maximum). 
Physiological concepts were the focus of the pre-lecture recordings. To check comprehension, self-assessment quizzes in multiple-choice question format were made available. Students were requested to undertake these quizzes before attending the flipped lectures. The lecturer would monitor the number of students who took the quiz, check their performance, and gauge which conceptual questions were easy or difficult for students. This way, the lecturer was able to emphasise, explain, and elaborate on areas students found challenging and needing support during the face to face flipped lecture.

\section{Research Design}

In order to evaluate the outcome/s of flipping a class, survey methodology was used at the conclusion of the study period. Questionnaires were administered to students online via the Survey Monkey to obtain information concerning their perceptions, experiences, and satisfaction or dissatisfaction of the flipped classroom. A pre-flip survey was also conducted at the beginning of the course to obtain pertinent student data.

This study was conducted at one of the three universities in Adelaide, South Australia.

An introductory letter was emailed to all on-campus nursing and midwifery students enrolled in the course informing them about the initiative. The lecturer invited students via email to participate in the surveys.

The impact of the flipped classroom was assessed using an instrument consisting of thirteen (13) statements on a Likert scale and two (2) open-ended questions. Specifically, the questionnaire examined students' views their experience with the teaching format, the learning that occurred, engagement with content and study materials, what they liked about it, impact on their test scores, and areas to improve the initiative. The approval of the University's Ethics Committee was sought and obtained for this study. Voluntary participation and confidentiality were ensured. Descriptive statistics and thematic analysis were used to analyse the data. 


\section{Findings}

Of the 532 internal students, 246 completed the pre-flip survey, representing a $46 \%$ response rate. Table 1 summarises the pre-flip survey that queried students' demographic details, science background, and awareness and experience of flipped classroom.

Table 1: Pre-flip survey results

\begin{tabular}{|l|c|}
\hline Question items & $\begin{array}{l}\text { Percentage } \\
\text { (\%) }\end{array}$ \\
\hline Little to reasonable science background & 43 \\
\hline Unaware of what flipped classroom is & 74 \\
\hline Had not experienced flipped classroom in the past & 95 \\
\hline Looking forward to flipped classroom & 45 \\
\hline English is first language & 80 \\
\hline Domestic student & 94 \\
\hline School leaver & 59 \\
\hline $\begin{array}{l}\text { First in the family to attend university } \\
\text { Did not identify as having an Aboriginal or Torres Strait Islander } \\
\text { background }\end{array}$ & 49 \\
\hline
\end{tabular}

Of the 532 students enrolled, 188 accomplished the post-flip survey, representing a $35 \%$ return rate. The table below indicates students' perceptions and experiences of the flipped classroom that were conducted.

Table 2: Post-flip survey results

\begin{tabular}{|l|c|}
\hline Question items & Percentage (\%) \\
\hline Course content was easier to understand through the flipped classroom style & 61 \\
\hline Rated the initiative positively (good 27\% / very good 32\%/excellent 26\%) & 86 \\
\hline Three most popular reasons chosen for liking flipped teaching: & \\
\hline View lecture recordings and other resources before the lecture & 60 \\
\hline Apply and check their understanding & 57 \\
\hline Clarify some concepts & 60 \\
\hline Students listened to pre-recorded lectures & 76 \\
\hline Attempted quizzes to test knowledge and understanding & 51 \\
\hline Prepared before traditional lectures & 53 \\
\hline Preferred flipped lectures to traditional lectures & 60 \\
\hline How flipped classroom could be improved: & 61 \\
\hline More time to prepare & 24 \\
\hline Flipped style used for all lectures & 33 \\
\hline No improvements necessary
\end{tabular}


There were several reasons for this positive appraisal gleaned from the open-ended responses, and these have been categorised into five themes. The themes, supported by the appropriate quotations describing them from the participants, are as follows:

Theme 1: Flipped classroom focused on students' learning needs

"With the lecture time, I was able to follow up to clarify any difficult concepts which was useful for my learning.”

"We spend our time at home learning the content, then we can come into the class and have that knowledge tested. It is also a better way to spend contact time with staff as we are given the opportunity to ask questions face to face."

Theme 2: Flipped classroom involved students' active participation

"I get to prepare before attending the lecture, I have an idea of what I'm going to be learning about, and identify areas I need to revise on further."

"... the fact that its broken down to more than one lecture is good, so I can watch the second and third another time. I am engaged in my learning."

Theme 3: Flipped classroom enhanced self-efficacy

"I think it really motivated my learning and made it easier to reflect on the information I was learning. "

"It gave me tools to help myself learn the human body."

Theme 4: Flipped classroom encouraged higher order of thinking

"Allows opportunity for discussion and analysis ... reinforcing what we have learnt."

"Introducing case scenarios in the flipped lecture enables us to see the relevance of science concepts for nursing practice. How science is relevant to nursing ..."

Theme 5: Flipped classroom made science fun

"I liked that they were interactive and we were given questions to reassure our learning and understanding. ” 
"It is fun and it provides an opportunity for students to check their understanding."

\section{Discussion and Conclusions}

Contemporary nurses and midwives need to be equipped with knowledge, skills and confidence in order for them to keep up with the fast pace of information and technology advancements. They need to be taught to think critically, assess, evaluate, update their knowledge, value evidence, develop problem-solving skills, and deliver appropriate, holistic, and patient-centred nursing/midwifery care. The reliance on traditional teaching methods such as lectures may be limiting students in addressing their educational needs.

This study demonstrated that implementing a flipped classroom was one strategy to meet the educational needs of future nurses and midwives. Findings revealed that there were positive outcomes for flipping a class. Five (5) themes emerged characterising the flipped classroom implemented for the students and these contributed to the learning that transpired impacting on the quality of students' learning experience. It was shown to be a promising instructional strategy, encouraging students to engage with the course content and with peers and lecturers, thus facilitating a high level of engagement and interaction. The initiative achieved time and space for student-student and student-academic to connect and interact more about a particular topic. Comments such as "They are engaging." "They're interesting." "Interactive learning is far more beneficial" were positive and encouraging for staff. Other authors corroborated these findings (Demetry 2010; Kim, Kim \& Khera 2013; See \& Conry 2014). These positive results resonated with the work the same authors undertook examining the perceptions of off-campus students on flipped classroom (Thalluri \& Penman 2016).

However, it is important to be cautious in interpreting the results because of the modest post-flip survey response rate of $35 \%$. More respondents will yield stronger reliable conclusions. Future directions for action include providing adequate orientation and clear objectives and expectations, continuous development of this initiative, and regular evaluations to ensure that maximum learning is achieved and course objectives are met. 


\section{References}

Author 1 and Author 2 (2016).

Baker, C. (2012). Flipped classrooms: turning learning upside down. Deseret News, [online], www.deseretnews.com/article/765616415/Flipped-classrooms-Turninglearning-upside-down.html?pg1/4all.

Barrett, D. (2012). How 'Flipping' the classroom can improve the traditional lecture. The Chronicle of Higher [online], moodle.technion.ac.il/file.php/1298/Announce/How_Flipping_the_Classroom_Can_Im prove_the_Traditional_Lecture.pdf.

Demetry, C. (2010). Work in progress - An innovation merging "Classroom flip" and teambased learning (Conference Paper), 40th Annual Frontiers in Education Conference: Celebrating Forty Years of Innovation, Arlington, VA, United States, 27-30 October, Article number 5673617, pp. T1E1-T1E2.

Educause Learning Initiative (2012) "7 things you should know about flipped classroom". [online], net.educause.edu/ir/library/pdf/pub7101.pdf.

Kim, M.K., Kim, S.M. and Khera, O. (2013). Exploring faculty and student experiences in the flipped classrooms. [online], University of Southern California, AECT-Flipped Classroom Presentation, cst.usc.edu/files/2013/07/AECT-Flipped-ClassroomPresentation-2013.pdf.

See, S. and Conry, J.M. (2014) "Flip my class! A faculty development demonstration of a flipped-classroom". ScienceDirect Currents in Pharmacy Teaching and Learning, Vol. 6, pp. 585-588.

Staker, H. and Horn, M. (2012). Classifying K-12 blended learning. [online], files.eric.ed.gov/fulltext/ED535180.pdf. 